\title{
International Development and Nonlinear Taxation in a Multi-Country Neoclassical Growth Model
}

\author{
Wei-Bin ZHANG
}

\begin{abstract}
This paper builds a multi-country growth model with nonlinear taxation and public goods. The dynamic machines of global development are national wealth accumulation and free trade. Different from most of theoretical growth models in neoclassical economics which deals with a two-country world and each economy has a homogeneous population, our model deals with any number of national economies and each economy has heterogeneous populations. A national economy consists of one industrial sector and one public sector and has any number of types of people. Our model integrates economic mechanisms of some well-known economic theories in a comprehensive framework. Each national economy is described according to Walrasian general economic theory. Capital accumulation follows the Solow model. Modelling public goods with nonlinear taxation is based on the literature of progressive taxation and economic growth. The trade pattern is modelled within the Oniki-Uzawa global growth model with two countries. We model household behavior on the basis of Zhang's concept of disposable income and utility function. We simulate the model to show transitory processes and long-term equilibrium. We carry out comparative dynamic analysis in some parameters.
\end{abstract}

KEYWORDS: heterogeneous households, international trade, neoclassical growth theory, nonlinear taxation, propensity to save.

JEL CLASSIFICATION: $B 17$.

\section{INTRODUCTION}

Economic theory has little to say about modern open economies. An obvious case is about current trade conflicts between the USA and China. A comprehensive discussion about the trade issues requires a dynamic general equilibrium framework with wealth. Nevertheless, the contemporary economic trade theory is a collection of unconnected partial economic theories with a few variables in each partial theory. Especially, economics fails to develop analytical frameworks suitable for addressing issues related to income and wealth distributions. We argue that it is necessary to develop economic theories which treat economic systems as a whole. This study develops a dynamic general equilibrium model with multiple national economies and heterogeneous households in each economy.

This study proposes a dynamic growth model with income and wealth distributions within and among countries. The analytical framework of this study is strongly influenced by neoclassical traditional dynamic one-commodity growth trade with perfect capital mobility. National economies are modelled on the basis of neoclassical growth theory (e.g., Burmeister and Dobell, 1970; Azariadis, 1993; Barro and Sala-i-Martin, 1995; Zhang, 2005, 2018). It is known that since the publication of the Oniki-Uzawa model of trade and economic growth by Oniki and Uzawa (1965), many trade growth models are developed within neoclassical growth theory (e.g., Stiglitz,

\footnotetext{
${ }^{1}$ Ritsumeikan Asia Pacific University, Japan, wbz1 @apu.ac.jp
} 
1970; Findlay, 1984; Eaton, 1987; Frankel and Romer, 1999; Baxter, 1992; Chen, 1992; Atkeson and Kehoe, 2000; Brecher, et al., 2002; Nishimura and Shimomra, 2002; Sorger, 2002; Nishimura et al., 2009). This study develops a trade model on the basis of the literature, but with an alternative approach to household behavior proposed by Zhang (1993, 2005). Another important feature of our approach is that each country has multiple groups of consumers in a national economy. This enables us to deal with issues related to wealth and income distribution (e.g., Chen and Ravallion, 1997; Barro, 2000; Tachibanaki, 2006). There are multigroup growth models of endogenous wealth in the literature of economic growth (e.g., Samuelson and Modigliani, 1966; Pasinetti, 1974; Galor and Zeira, 1993; Acemoglu, 2002; Aghion et al., 2002). Nevertheless, there are few trade model of heterogeneous households in the international growth literature. Our global growth model with heterogeneous households allows us to examine issues about effects of trade upon domestic as well as international income and wealth distribution.

Another important issue this paper addresses is how government's spending affects economic growth, trade pattern, and wealth and income distributions (Barro, 1990; Turnovsky, 2000, 2004). We are especially concerned with progressive income taxation (e.g., Glomm and Ravikumar, 1997; Agénor, 2011; Baier and Glomm, 2001; Palivos et al., 2003; Greiner, 2007; Hu et al., 2008; and Chen and Guo, 2013, 2014). This paper deviates from traditional approaches by applying Zhang's concept of disposable income and utility function (Zhang, 1993, 2005). We introduce nonlinear progressive income taxation to the dynamic Walrasian general equilibrium model with multiple countries. It should be also mentioned that this study is a synthesis of two models by Zhang (1994, 2015). The model by Zhang (2015) makes taxation on the household's income an endogenous variable. Zhang's 1994 model deals with a multi-country model with endogenous wealth. Zhang's 2005 model introduces progressive taxation into neoclassical growth theory with Zhang's concept of disposable income and utility function. This paper is organized as follows. Section 2 develops a multi-country growth model with endogenous wealth and progressive taxation. Section 3 examines properties of the model. Section 4 conducts comparative dynamic analysis in some parameters. Section 5 concludes the study.

\section{THE GLOBAL GROWTH MODEL WITH NONLINEAR TAXATION}

We basically follow neoclassical trade growth model with capital accumulation. The world consists of any number of national economies. National countries are indexed by $j=1, \ldots, J$. The world produces a homogenous commodity which can be used for consumption and investment (e.g., Ikeda and Ono, 1992). Each national economy composes of two sectors. The industrial sector produces the tradable commodity and the public sector supplies public services which are used domestically by households. Technologies of the two sectors are neoclassical (e.g., Zhang, 2005, 2008). Households own assets and distribute their disposable incomes between consuming and saving. The production and economic mechanisms of price determination are neoclassical. International exchanges are conducted in perfectly competitive markets. We measure prices in terms of the capital good. Perfect competition is assumed to prevail in good markets both within each country and between the countries. There is no migration between the countries. We assume that the population of country $j$ can be classified into $Q_{j}$ groups, according to their preferences, wealth, human capital, and social status. The total number of household types $Q$ in the world economy is given by $Q=\sum_{j=1}^{J} Q_{j}$. A group $q$ in country $j$ is indexed by $(j, q)$. We introduce 


$$
Q^{*} \equiv\left\{(j, q) \mid j=1, \cdots, J, q=1, \cdots, Q_{j}\right\}
$$

We introduce variables as follows:

$i$ and $p$ - subscript index for industrial and public sectors, respectively; $\bar{N}_{j q}$ and $N_{j}$ - population of group $(j, q)$ and labor force of country $j$;

$r(t)$ and $w_{j q}(t)$ - globally equal rate of interest and wage rate of worker $(j, q)$;

$s_{j q}(t)$ and $\bar{k}_{j q}(t)$ - saving made by and wealth owned by household $(j, q)$;

$c_{j q}(t)$ - consumption level of good by household $(j, q)$;

$K(t)$ and $\bar{K}_{j}(t)$ - capital stocks of the world economy and capital owned by country $j$;

$K_{j}(t)$ - total capital stock employed by country $j$;

$G_{j}(t)$ - output of country $j^{\prime} s$ public sector;

$F_{j m}(t)$ - output level of country $j^{\prime} s$ sector $m, m=i, p$;

$K_{j m}(t)$ and $N_{j m}(t)$ - capital stock and labor input employed by country $j^{\prime} s$ sector $m, m=i, p$;

$\delta_{k j}$ - depreciation rate of physical capital in country $j$.

The labor force $N_{j}$ of country $j$ is

$$
N_{j}=\sum_{q=1}^{Q_{j}} h_{j q} N_{j q}
$$

where $h_{j q}$ are the level of human capital of household $(j, q)$.

\section{Industrial Sectors}

We describe the technologies of industrial sectors with the following Cobb-Douglas production functions:

$$
F_{j i}(t)=A_{j i} K_{j i}^{\alpha_{j i}}(t) N_{j i}^{\beta_{j i}}(t), \theta_{j}>0, A_{j i}, \alpha_{j i}, \beta_{j i}>0, \alpha_{j i}+\beta_{j i}=1,
$$

where $A_{j i}, \alpha_{j i}$, and $\beta_{j i}$ are parameters. The marginal conditions

$$
r(t)+\delta_{k j}=\frac{\alpha_{j i} F_{j i}(t)}{K_{j i}(t)}, \quad w_{j}(t)=\frac{\beta_{j i} F_{j i}(t)}{N_{j i}(t)}
$$

\section{Current Income and Disposable Income}

We apply Zhang's concept of disposable income and utility function to model consumers' behavior (Zhang, 1993, 2008). Wage incomes $W_{j q}(t)$ of household $(j, q)$ are given as

$$
W_{j q}(t)=h_{j q} w_{j q}(t)
$$


Let $\bar{k}_{j q}(t)$ stand for the capital stock owned by household $(j, q)$. If there is no taxation on household's current incomes households receive incomes from interest payments and wage payments is

$$
y_{0 j q}(t)=r(t) \bar{k}_{j q}(t)+W_{j q}(t)
$$

Following Chen and Guo (2014) and Zhang (2015), we consider a nonlinear progressive tax rate $\tau_{j q}(t)$ as a function of $y_{0 j}(t)$ as follows

$$
\tau_{j q}(t)=b_{j q}+\tilde{b}_{j q} y_{0 j q}^{a_{j q}}(t), \quad 1>\bar{\tau}_{j q}, b_{j q}>0, \tilde{b}_{j q}>0
$$

In the case of $a_{j q}>0$ the tax rate rises with the current income. The tax schedule is said to be progressive. In the case of $a_{j q}=0$ the tax schedule is called flat. There are many studies which assume constant tax rates or flat consumption taxes (e.g., Cazzavillan, 1996; Zhang, 2000; Raurich, 2003; Fernández et al. 2004; Chen, 2006; Guo and Harrison, 2008). This study considers progressive taxation. The current income of household $(j, q)$ is then given by

$$
y_{j q}(t)=\bar{\tau}_{j q}(t) y_{0 j q}(t)
$$

where $\bar{\tau}_{j q}(t) \equiv 1-\tau_{j q}(t)$. The total value of wealth that household $(j, q)$ owns is $\bar{k}_{j q}(t)$. We assume that selling and buying wealth can be conducted instantaneously without any transaction cost. The disposable income $\hat{y}_{j q}(t)$ is the sum of the current income and the wealth value

$$
\hat{y}_{j q}(t)=y_{j q}(t)+\bar{k}_{j q}(t) \text {. }
$$

The disposable income is distributed between consumption $c_{j q}(t)$ and saving $s_{j q}(t)$. The budget constraint of household $(j, q)$ is as follows:

$$
c_{j q}(t)+s_{j q}(t)=\hat{y}_{j q}(t)
$$

\section{Utility Functions}

Consumers make decisions on consumption levels of commodities and on levels of savings. We assume that utility level $U_{j q}(t)$ is dependent on the consumption level of commodity and savings as follows:

$$
U_{j q}(t)=u_{j q}\left(G_{j}(t), t\right) c_{j q}^{\xi_{0 j q}}(t) s_{j q}^{\lambda_{0 j q}}(t), \quad \xi_{0 j q}, \lambda_{0 j q}>0
$$

where $u_{j q}$ is dependent on the level of public services, $\xi_{0 j q}$ and $\lambda_{0 j q}$ are called respectively the propensities to consume good and to hold wealth.

\section{The Household's Optimal Behaviour}

Maximizing $U_{j q}$ subject to budget constraint (8) yields

where

$$
c_{j q}(t)=\xi_{j q} \hat{y}_{j q}(t), s_{j q}(t)=\lambda_{j q} \hat{y}_{j q}(t)
$$

$$
\rho_{j q} \equiv \frac{1}{\xi_{0 j q}+\lambda_{0 j q}}, \quad \xi_{j q} \equiv \rho_{j q} \xi_{0 j q}, \lambda_{j q} \equiv \rho_{j q} \lambda_{0 j q}
$$




\section{Wealth Accumulation}

According to the definitions of $s_{j q}(t)$, change in wealth is described by

$$
\dot{\bar{k}}_{j q}(t)=s_{j q}(t)-\bar{k}_{j q}(t),(j, q) \in Q^{*} .
$$

\section{The Public Sector}

As in Zhang (2015), each country's public sector is solely financed by the country's tax income. The input factors of the public sector are paid at the same rates that these factors receive from the private sector. The tax income is

$$
I_{j p}(t)=\sum_{q}\left[r(t) \bar{k}_{j q}(t)+w_{j q}(t)\right] \tau_{j q}(t) N_{j q}(t) .
$$

Production of the public sector is taken on the following Cobb-Douglas form as follows

$$
G_{j}(t)=A_{j p} K_{j p}^{\alpha_{j p}}(t) N_{j p}^{\beta_{j p}}(t), A_{j p}, \alpha_{j p}, \beta_{j p}>0, \alpha_{j p}+\beta_{j p}=1 .
$$

We have the budget constraint of the public sector as follows

$$
w_{j}(t) N_{j p}(t)+\left(r(t)+\delta_{j k}\right) K_{j p}(t)=I_{j p}(t)
$$

Maximizing public services subject to the budget constraint yields the following marginal conditions:

$$
\frac{\alpha_{j p} N_{j p}(t)}{\beta_{j p} K_{j p}(t)}=\frac{r(t)+\delta_{j k}}{w_{j}(t)}
$$

\section{The Factors are Fully Employed}

Each country fully employs its input factors

$$
K_{j i}(t)+K_{j p}(t)=K_{j}(t), N_{j i}(t)+N_{j p}(t)=N_{j} .
$$

\section{The National and International Wealth}

The national wealth $\bar{K}_{j}(t)$ is the sum of the wealth owned by all the households in the country

$$
\bar{K}_{j}(t)=\sum_{q} \bar{k}_{j q}(t) N_{j q}
$$

Global wealth and capital balance

$$
K(t)=\sum_{j=1}^{J} \bar{K}_{j}(t)=\sum_{j=1}^{J} K_{j}(t) .
$$

\section{Balances in Good Markets}

The world output is the sum of the net savings and the depreciations of capital

$$
S(t)-K(t)-C(t)+\sum_{j=1}^{J} \delta_{k j} K_{j}(t)=\sum_{j=1}^{J} F_{j i}(t),
$$

where 


$$
S(t)=\sum_{j=1}^{J} s_{j}(t) \bar{N}_{j}, C(t)=\sum_{j=1}^{J} c_{j}(t) \bar{N}_{j} .
$$

We define the trade balances as:

$$
B_{j}(t)=\left(\bar{K}_{j}(t)-K_{j}(t)\right) r(t)
$$

When $B_{j}(t)$ is positive (negative), country $j$ is in trade surplus (deficit). When $B_{j}(t)$ is zero, country $j^{\prime} s$ trade is in balance.

The model is completed. The dynamic general equilibrium model is based on some well-known dynamic models in the literature of economic theory. These models may be also considered as special cases of our model. The rest of the paper studies dynamic properties of the model.

\section{THE DYNAMIC PROPERTIES}

The previous section developed a multi-country model with nonlinear taxation and public goods. The model is nonlinear and highly dimensional. It is analytically too complicated to get its general properties. We simulate the model to show some properties of the model. We give a computational program to follow the motion of the system. We introduce variables

$$
z_{1}(t) \equiv \frac{r(t)+\delta_{k 1}}{w_{1}(t)}, \quad\left\{\bar{k}_{j}(t)\right\} \equiv\left(\bar{k}_{2}(t), \ldots, \bar{k}_{J}(t)\right)
$$

The following Lemma gives a set of differential equations for us to determine the movement of $z_{1}(t)$ and $\left\{\bar{k}_{j}(t)\right\}$.

\section{Lemma}

The dynamics of $z_{1}(t)$ and $\left\{\bar{k}_{j}(t)\right\}$ is determined by following differential equations

$$
\begin{gathered}
\dot{z}_{1}(t)=\Omega_{11}\left(z_{1}(t),\left\{\bar{k}_{j}(t)\right\}\right), \\
\dot{\bar{k}}_{j q}(t)=\Omega_{j q}\left(z_{1}(t),\left\{\bar{k}_{j}(t)\right\}\right), \quad j=2, \ldots, J, q=1, \ldots, Q_{j},
\end{gathered}
$$

where $\Omega_{j q}(t)$ are functions of $z_{1}(t)$ and $\left\{\bar{k}_{j}(t)\right\}$ defined in the Appendix. The other variables are given as functions of $z_{1}(t)$ and $\left\{\bar{k}_{j}(t)\right\}$ as follows: $r(t)$ and $w_{j}(t)$ with $(\mathrm{A} 2) \rightarrow w_{j q}(t)$ and $z_{j}(t)$ from $(\mathrm{A} 3) \rightarrow \bar{k}_{1}(t)$ by (A10) $\rightarrow y_{0 j q}(t)$ by (4) $\rightarrow \tau_{j q}(t)$ by (5) $\rightarrow y_{j q}(t)$ by (6) $\rightarrow \hat{y}_{j q}(t)$ by (6) $\rightarrow c_{j q}(t)$ and $s_{j q}(t)$ by (9) $\rightarrow I_{j q}(t)$ by (11) $\rightarrow G_{j}(t)$ by (12) $\rightarrow N_{j p}(t)$ by (A4) $\rightarrow N_{j i}(t)$ by $(15) \rightarrow K_{j m}(t)$ by (A1) $\rightarrow F_{j i}(t)$ by (2) $\rightarrow K_{j}(t)$ by (14) $\rightarrow \bar{K}_{j}(t)$ by (15) $\rightarrow B_{j}(t)$ by (18).

System (18) is composed of $J$ nonlinear differential equations. The system contains the same number of endogenous variables. We simulate the model to show the movement of the system. The parameters of the production functions and depreciation rates of physical capital are taken on the following values:

$$
\left(\begin{array}{l}
A_{1 i} \\
A_{2 i} \\
A_{3 i}
\end{array}\right)=\left(\begin{array}{c}
1 \\
1.2 \\
1
\end{array}\right),\left(\begin{array}{l}
A_{1 p} \\
A_{2 p} \\
A_{3 p}
\end{array}\right)=\left(\begin{array}{l}
1.3 \\
1.1 \\
0.8
\end{array}\right),\left(\begin{array}{c}
\alpha_{1 i} \\
\alpha_{2 i} \\
\alpha_{3 i}
\end{array}\right)=\left(\begin{array}{c}
0.3 \\
0.32 \\
0.34
\end{array}\right),\left(\begin{array}{l}
\alpha_{1 p} \\
\alpha_{2 p} \\
\alpha_{3 p}
\end{array}\right)=\left(\begin{array}{c}
0.25 \\
0.27 \\
0.3
\end{array}\right),\left(\begin{array}{l}
\delta_{1} \\
\delta_{2} \\
\delta_{3}
\end{array}\right)=\left(\begin{array}{l}
0.05 \\
0.06 \\
0.07
\end{array}\right),
$$


The total productivity factors of the two sectors are different between countries. In many studies of economic growth (e.g., Miles and Scott, 2005; Abel et al, 2007) the value of $\alpha$ in the Cobb-Douglas production function is approximately 0.3. Human capital utilization efficiencies and depreciation rates of human capital are specified as follows:

$$
\left(\begin{array}{l}
m_{11} \\
m_{21} \\
m_{31}
\end{array}\right)=\left(\begin{array}{c}
0.75 \\
0.65 \\
0.6
\end{array}\right),\left(\begin{array}{l}
m_{12} \\
m_{22} \\
m_{32}
\end{array}\right)=\left(\begin{array}{c}
0.65 \\
0.5 \\
0.45
\end{array}\right),\left(\begin{array}{l}
\delta_{11} \\
\delta_{21} \\
\delta_{31}
\end{array}\right)=\left(\begin{array}{c}
0.035 \\
0.045 \\
0.05
\end{array}\right),\left(\begin{array}{l}
\delta_{12} \\
\delta_{22} \\
\delta_{32}
\end{array}\right)=\left(\begin{array}{c}
0.045 \\
0.045 \\
0.05
\end{array}\right),
$$

The preferences, levels of human capital, and sizes of the population are specified as follows:

$$
\begin{aligned}
& \xi_{j q 0}=0.2, \lambda_{j q 0}=0.5 \\
& \left(\begin{array}{l}
h_{11} \\
h_{12} \\
h_{21}
\end{array}\right)=\left(\begin{array}{l}
6 \\
4 \\
4
\end{array}\right),\left(\begin{array}{l}
h_{22} \\
h_{31} \\
h_{32}
\end{array}\right)=\left(\begin{array}{c}
2 \\
2 \\
1.5
\end{array}\right),\left(\begin{array}{l}
N_{11} \\
N_{12} \\
N_{21}
\end{array}\right)=\left(\begin{array}{l}
100 \\
200 \\
200
\end{array}\right),\left(\begin{array}{l}
N_{22} \\
N_{31} \\
N_{32}
\end{array}\right)=\left(\begin{array}{l}
300 \\
400 \\
500
\end{array}\right) .
\end{aligned}
$$

Countries the same in preferences. We will allow the preferences to vary and examine how the differences affect the national and global economies. The parameters for nonlinear taxation are specified as follows:

$$
\begin{aligned}
& \left(\begin{array}{l}
b_{11} \\
b_{12} \\
b_{21}
\end{array}\right)=\left(\begin{array}{l}
0.05 \\
0.03 \\
0.04
\end{array}\right),\left(\begin{array}{l}
b_{22} \\
b_{31} \\
b_{32}
\end{array}\right)=\left(\begin{array}{l}
0.03 \\
0.04 \\
0.03
\end{array}\right),\left(\begin{array}{l}
\tilde{b}_{11} \\
\widetilde{b}_{12} \\
\widetilde{b}_{21}
\end{array}\right)=\left(\begin{array}{c}
0.01 \\
0.005 \\
0.01
\end{array}\right),\left(\begin{array}{l}
\tilde{b}_{22} \\
\widetilde{b}_{31} \\
\widetilde{b}_{32}
\end{array}\right)=\left(\begin{array}{c}
0.006 \\
0.01 \\
0.005
\end{array}\right),\left(\begin{array}{l}
a_{11} \\
a_{12} \\
a_{21}
\end{array}\right)=\left(\begin{array}{c}
1 \\
0.5 \\
1.1
\end{array}\right), \\
& \left(\begin{array}{l}
a_{22} \\
a_{31} \\
a_{32}
\end{array}\right)=\left(\begin{array}{l}
0.8 \\
1.1 \\
0.7
\end{array}\right) .
\end{aligned}
$$

If we consider the disposable incomes are zero, the tax rates are relatively low. The tax rates are influenced, but not very strongly, by the disposable incomes. To follow the motion of the system, we specify the initial conditions:

$$
z_{1}(0)=0.081, \bar{k}_{12}(t)=22, \bar{k}_{21}(t)=13.5, \bar{k}_{22}(t)=8, \bar{k}_{31}(t)=5.6, \bar{k}_{32}(t)=4.3 .
$$

The simulation result given in Figure 1. In the figure we introduce the global output as follows:

$$
Y(t) \equiv F_{1 i}(t)+F_{2 i}(t)+F_{3 i}(t)
$$

The global output and global wealth rise from their low initial conditions. The rate of interest falls in association with the rise in the global capital. Due to the initial states fixed, we observe that the national economies do not converge over time. Although there are varied opinions about whether nations' economic performances will converge or not (e.g., Caselli et al., 1996; Pritchett, 1997; Jones, 1997; Hall and Jones, 1999; Cameron et al., 2005; Grier and Grier, 2007; Bos et al., 2010), our result shows that if no parameter is changed, nations' economic performances will not converge. We will examine how nations' economic performances will be affected as some parameters are changed. 

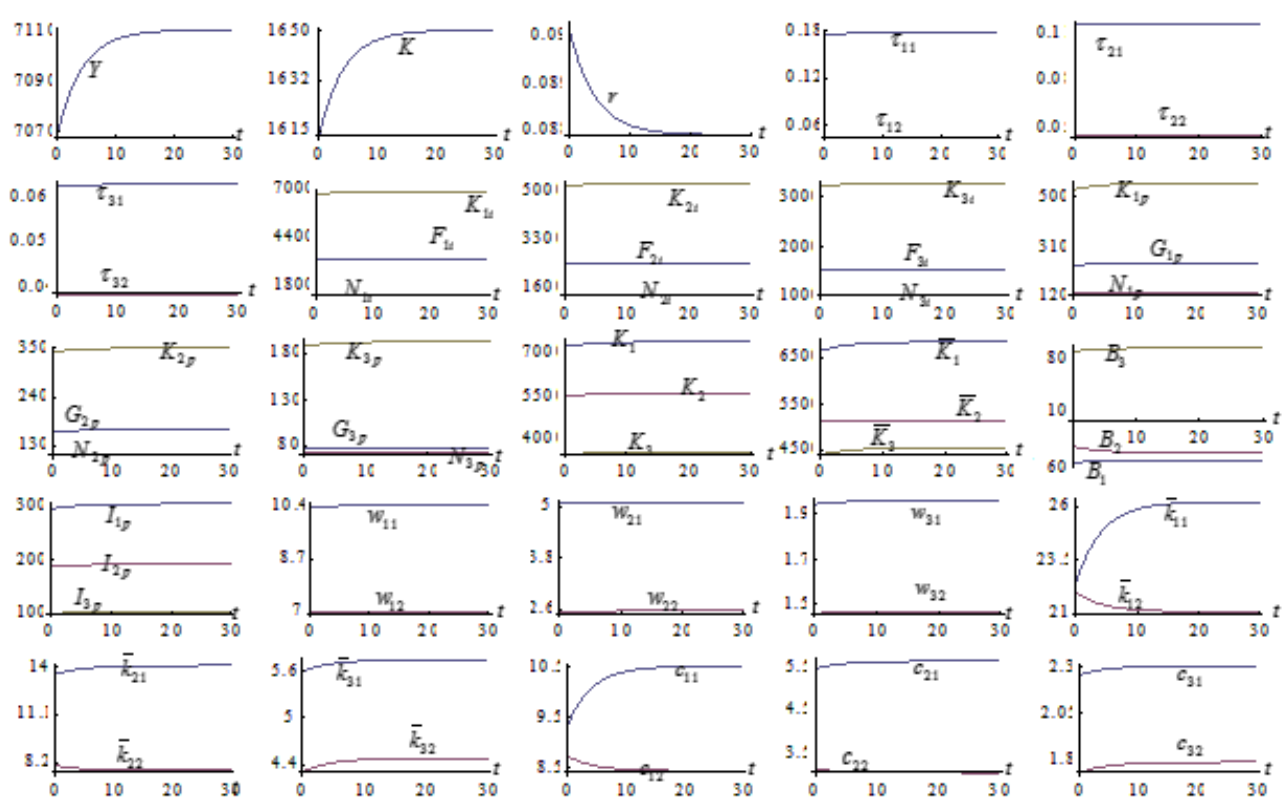

Figure 1. The Motion of the Economic System

Source: Author

From Figure 1 we observe that the system becomes stationary in the long term. The simulation shows the following value of an equilibrium point:

$$
\begin{aligned}
& Y=7110.2, \quad K=16501.2, \quad r=0.087, \quad \tau_{11}=0.178, \tau_{12}=0.116, \tau_{21}=0.067, \\
& \tau_{22}=0.045, \tau_{31}=0.045, \tau_{32}=0.038, \quad F_{1 i}=3158.3, \quad F_{2 i}=2426.3, \quad F_{3 i}=1525.6 \text {, } \\
& G_{1 p}=245.2, G_{2 p}=164.8, G_{3 p}=77.6, \quad K_{1 i}=6870.4, K_{2 i}=5249.2, K_{3 i}=3284.9 \text {, } \\
& K_{1 p}=554.6, K_{2 p}=349.9, \quad K_{3 p}=192.3, \quad N_{1 i}=1268.4, \quad N_{2 i}=1290.5, \quad N_{3 i}=1027.7 \text {, } \\
& N_{1 p}=131.6, N_{2 p}=109.5, N_{3 p}=72.3, K_{1}=7425, K_{2}=5599.1, K_{3}=3477 \text {, } \\
& \bar{K}_{1}=6838.8, \bar{K}_{2}=5120.6, \bar{K}_{3}=4541.8, B_{1}=-51.5, B_{2}=-42.1, B_{3}=59.6 \text {, } \\
& I_{1 p}=306, I_{2 p}=191.7, I_{3 p}=101.2, w_{11}=10.5, w_{21}=5.1, w_{31}=2, w_{12}=7 \text {, } \\
& w_{22}=2.6, w_{32}=1.5, \bar{k}_{11}=26.2, \bar{k}_{21}=14, \bar{k}_{31}=5.8, \bar{k}_{12}=21.1, \bar{k}_{22}=7.7 \text {, } \\
& \bar{k}_{32}=4.5, c_{11}=10.5, c_{21}=5.6, c_{31}=2.3, c_{12}=8.4, c_{22}=3.1, c_{32}=1.8 \text {. }
\end{aligned}
$$

The eigenvalues at equilibrium point are as follows:

$$
-0.241,-0.234,-0.228,-0.226,-0.225,-0.223 \text {. }
$$

All the eigenvalues are negative. This implies that the equilibrium point is locally stable. We can thus effectively conduct locally dynamic comparative analysis.

\section{COMPARATIVE DYNAMIC ANALYSIS}

We simulated the movement of the global economy. We now study how changes in some economies' preferences or technologies affect transitory processes and long-term economic development. As we have the computational procedure to calibrate the system over time, we can 
easily examine effects of changes in any parameter on transitory processes and equilibrium values of all the variables. We define a variable $\bar{\Delta} x_{j}(t)$ to represent the change rate of the variable, $x_{j}(t)$, in percentage due to changes in the parameter value.

\subsection{The Total Productivity Factors are Enhanced}

We now examine the effects that the total productivity factors of the three countries' industrial sectors are enhanced as follows:

$$
A_{1 i}: 1.5 \Rightarrow 1.55, A_{2 i}: 1.2 \Rightarrow 1.25, \quad A_{3 i}: 1 \Rightarrow 1.05
$$

The result is given in Figure 2. All the three industrial sectors' output levels and capital stocks are augmented. The rate of interest rises initially and changes slightly in the long term. The industrial sectors employ less labor forces and the public sectors have more labor forces. The tax rates on all the households are increased. The three public sectors increase output levels and employ more capital stocks. The three economies employ more capital stocks and own more wealth. Country 1's trade balance is improved initially and deteriorated in the long term. The other two economies' trade balances are initially deteriorated and improved in the long term. The three economies have more tax incomes. The wage rates are enhanced. All the households have more wealth and consume more goods.
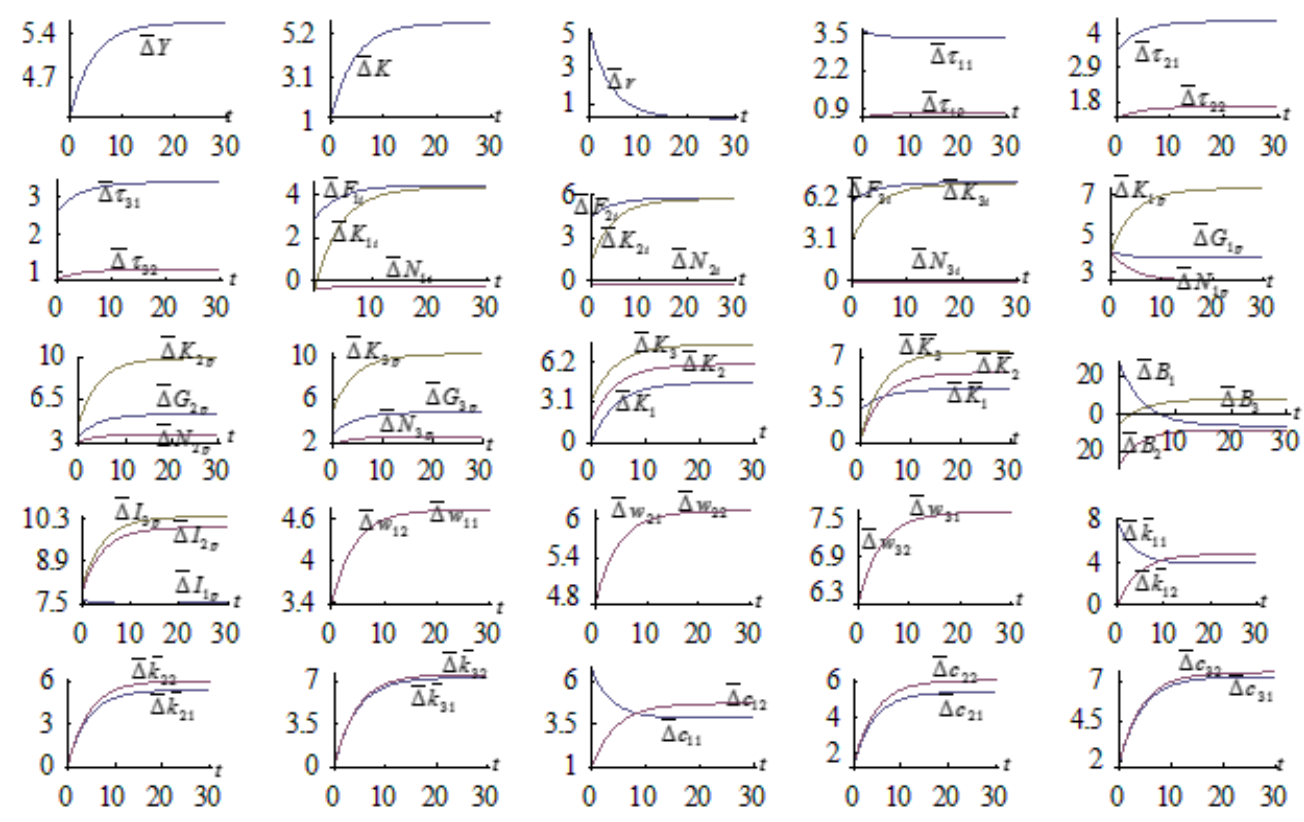

Figure 2. The Total Productivity Factors Are Enhanced Source: Author 


\subsection{Countries 2 and 3 Enhance Propensities to Save}

We now study how the national and global economies are affected when household $(2,1)$ and household $(3,1)$ enhance their propensities to save as follows:

$$
\lambda_{21}: 0.5 \Rightarrow 0.51, \quad \lambda_{2 i}: 0.5 \Rightarrow 0.51
$$
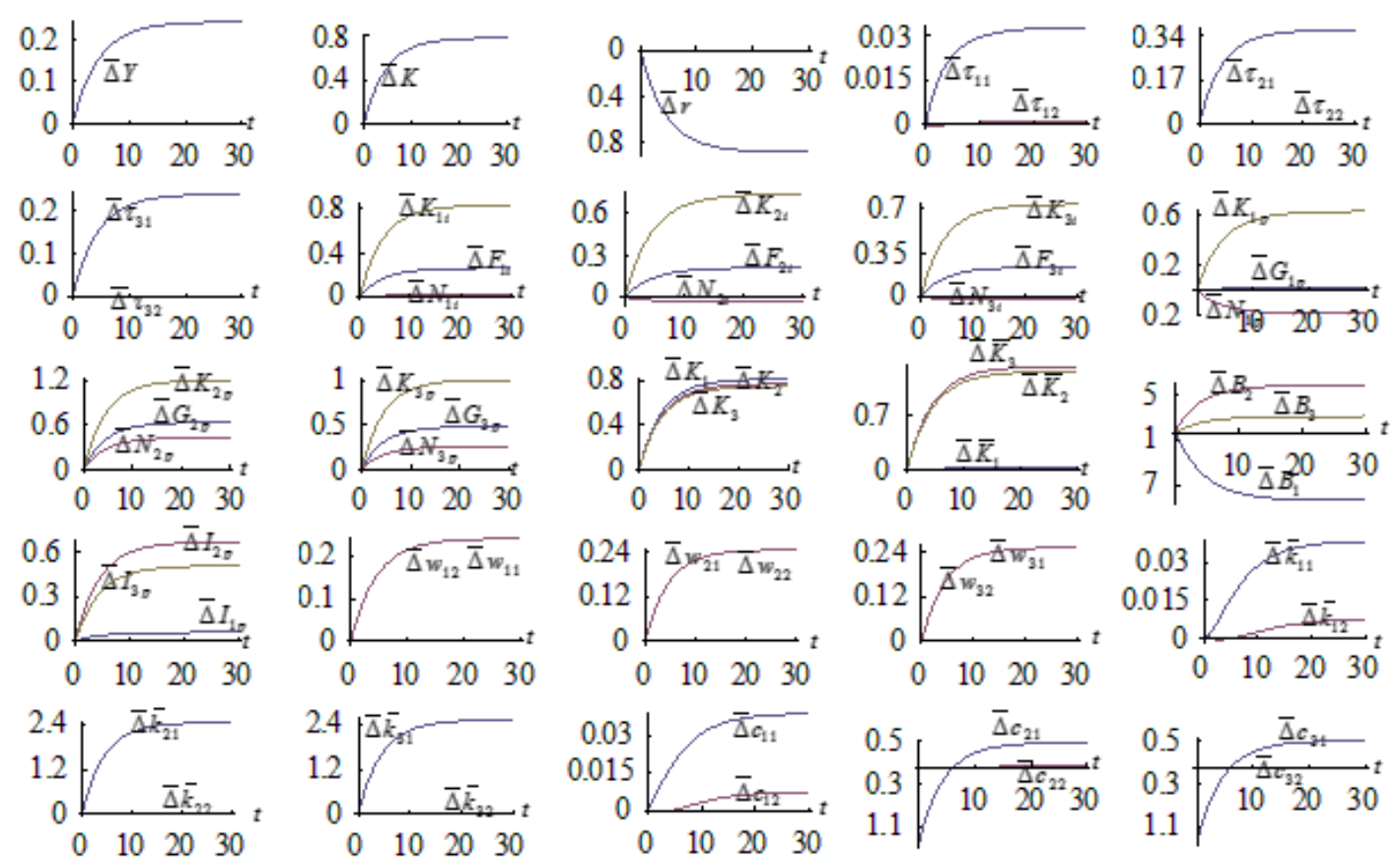

Figure 3. Countries 2 and 3 Enhance Propensities to Save Source: Author

The result is plotted in Figure 3. The global output and wealth are augmented. The rate of interest falls. The tax rates on household $(2,1)$ and household $(3,1)$ are enhanced, while the tax rates on the other groups are slightly affected. The three industrial sectors' output levels are increased. The capital stocks employed by the three industrial sectors are increased. The labor distributions are slightly affected. The three economies employ more capital. The capital stocks owned by country is slightly changed, while the capital stocks owned by the other two economies are increased. The wage rates are increased. Country 1's trade balance is deteriorated, while the other two economies' trade balances are improved. Household $(2,1)$ and household $(3,1)$ have more wealth. Household $(2,1)$ and household $(3,1)$ consume less initially and more in the long term.

\subsection{Household $(2,1)$ and Household $(3,1)$ Enhance Human Capital}

We now examine how the national and global economies are changed when household $(2,1)$ and household $(3,1)$ enhance their human capital as follows:

$$
h_{21}: 4 \Rightarrow 4.11, h_{31}: 2 \Rightarrow 2.1 .
$$


The result is plotted in Figure 4.
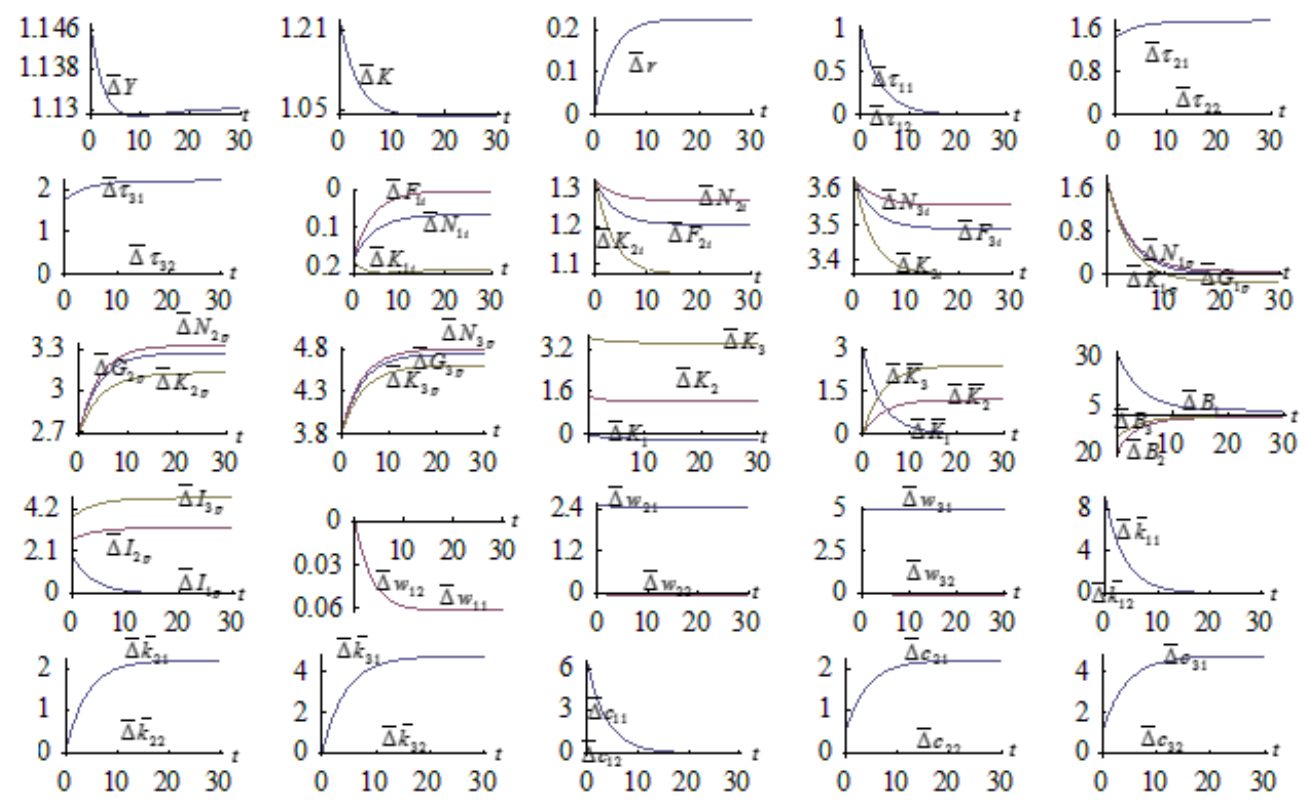

Figure 4. Household $(2,1)$ and Household $(3,1)$ Enhance Human Capital Source: Author

The global output and wealth are augmented. The rate of interest rises. The tax rates on household $(2,1)$ and household $(3,1)$ are enhanced, while the tax rates on the other groups are slightly affected. Countries 2 and 3's industrial sectors and public sectors are expanded. Country 1' output level falls initially and slightly changes in the long term. Country 1's industrial sector employs less capital and labor force. Country 1's public sector augments output and employs more input factors initially and reduces output and employs less input factors in the long term. Country 1 employs slightly less capital stocks and the other two countries more capital stocks. Country 1's wealth rises initially and changes slightly in the long term. The other two countries' wealth levels fall. The capital stocks employed by the three industrial sectors are increased. The labor distributions are slightly affected. The three economies employ more capital. The capital stocks owned by country is slightly changed, while the capital stocks owned by the other two economies are increased. The wage rates are increased. The trade balances are disturbed initially and changed slightly. Household $(2,1)$ and household $(3,1)$ have higher wage rates and more wealth and consume more. The other households' wealth, consumption levels, and wage rates are slightly affected in the long term.

\subsection{The Public Sectors' Elasticities of Outputs for Capital are Enhanced}

We now analyze the impact of the following changes in the public sectors' elasticities of outputs for capital:

$$
\alpha_{1 p}: 0.25 \Rightarrow 0.26, \alpha_{2 p}: 0.27 \Rightarrow 1.25, \alpha_{3 p}: 0.3 \Rightarrow 0.31
$$

The result is given in Figure 5. The global output and wealth rise initially and change slightly. The labor forces are shifted from the industrial sectors to the public sectors. The tax rates are slightly affected. The public sectors employ less capital stocks and increase output levels. The industrial sectors augment output levels initially and change slightly in the long term. The wage rates are reduced. All the households have slight changes in wealth and consumption. 


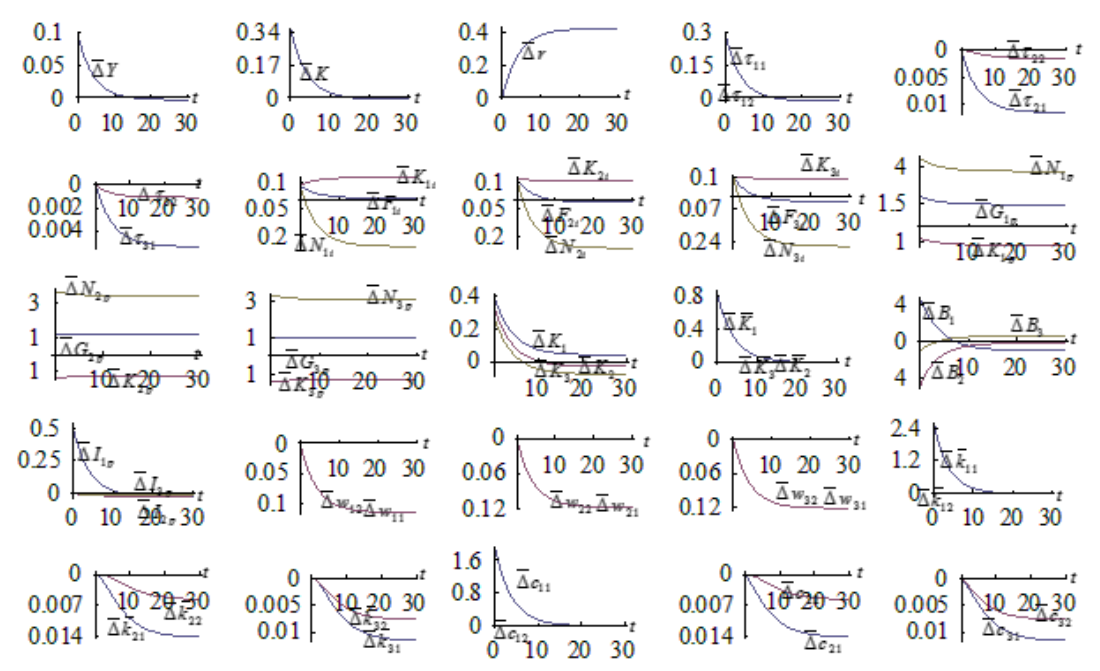

Figure 5. The Public Sectors' Elasticities of Outputs for Capital are Enhanced Source: Author

\subsection{The Populations of Group $(2,1)$ and Group $(3,1)$ are Increased}

We now examine how the national and global economies are changed when the populations of group $(2,1)$ and group $(3,1)$ are increased as follows:

$$
N_{21}: 200 \Rightarrow 210, \quad N_{31}: 400 \Rightarrow 410 .
$$

The result is plotted in Figure 5. We see that the changes in the populations have strong impact on the macroeconomic variables. The changes have little effects on the tax rates and wage rates. The microeconomic variables are slightly affected.

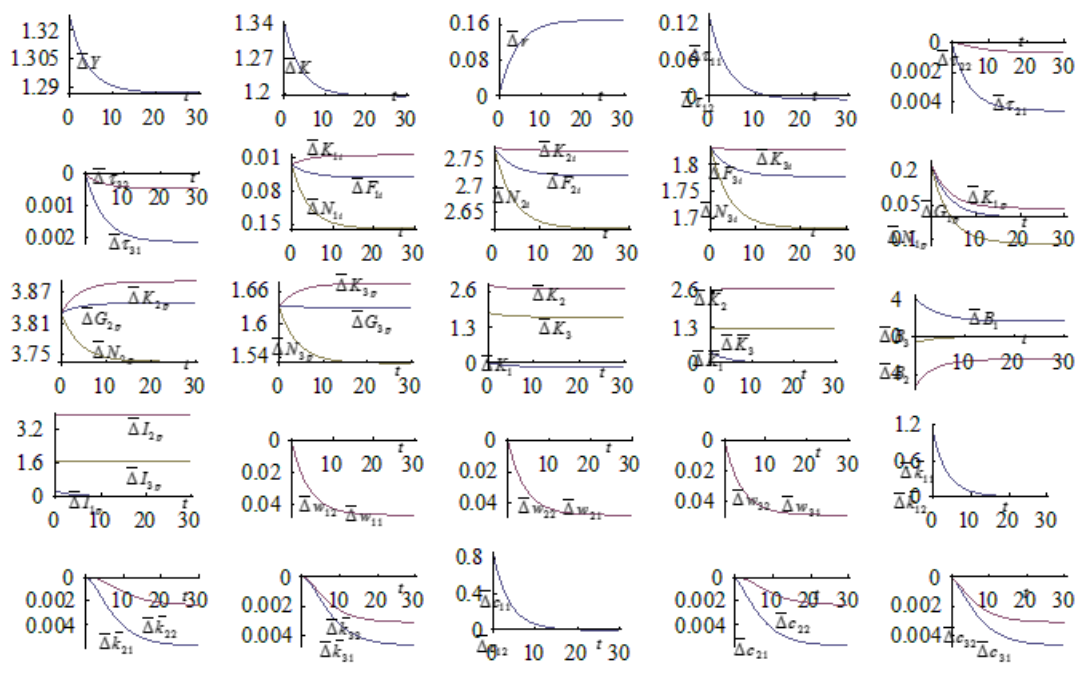

Figure 6. The Populations of Group $(2,1)$ and $\operatorname{Group}(3,1)$ are Increased Source: Author

\subsection{The Constant Parts of Group (j, 1)s' Taxation Equations are Increased}

The constant parts of group $(\mathrm{j}, 1) \mathrm{s}$ ' taxation equations are increased as follows:

$$
b_{11}: 0.05 \Rightarrow 0.06, b_{21}: 0.04 \Rightarrow 0.05, b_{31}: 0.04 \Rightarrow 0.05 \text {. }
$$

The result is plotted in Figure 7. The global output and wealth are reduced. The rate of interest rises. The tax rates on households $(\mathrm{j}, 1) \mathrm{s}$ are increased. The public sectors expand. The industrial 
sectors shrink. The economies employ less capital stocks and have less wealth. In the long term country 1's trade balance is improved, while the other two countries' trade balances are deteriorated. The wage rates are reduced. The households on whom taxation has become heavier have less wealth and consume less. The other households' wealth and consumption levels are slightly changed.

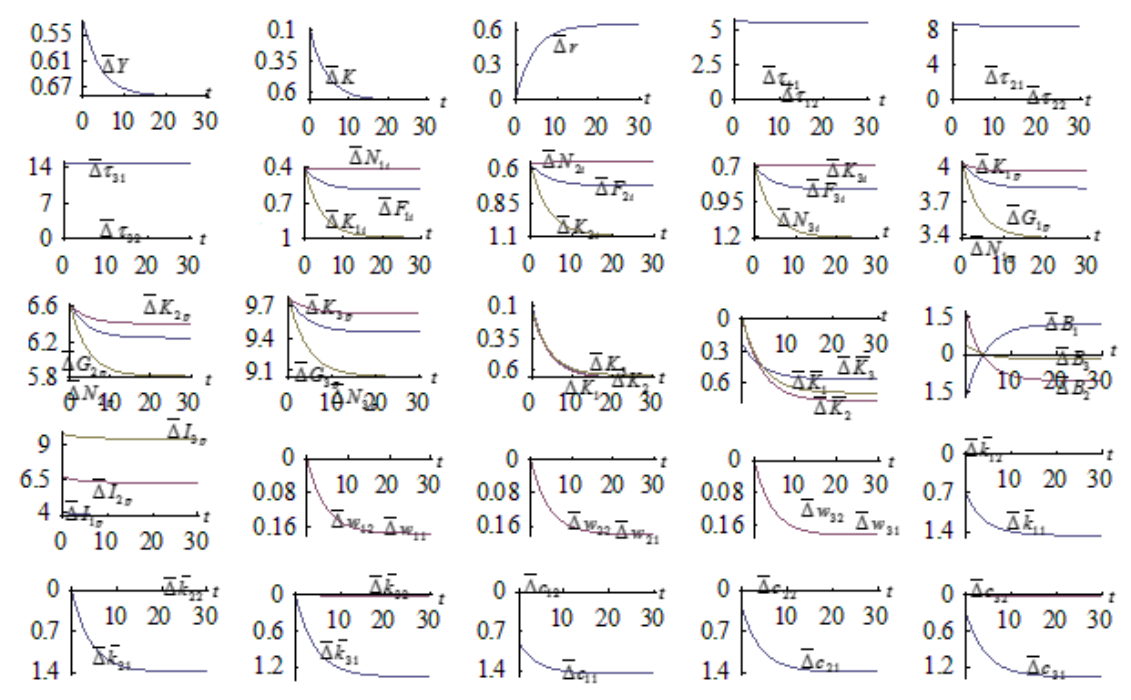

Figure 7. The Constant Parts of Group $(j, 1)$ s' Taxation Equations are Increased Source: Author

\subsection{The Power Parameters in Group (j, 2)s' Taxation Equations are Reduced}

The power parameters in group $(\mathrm{j}, 2) \mathrm{s}^{\prime}$ taxation equations are reduced as follows:

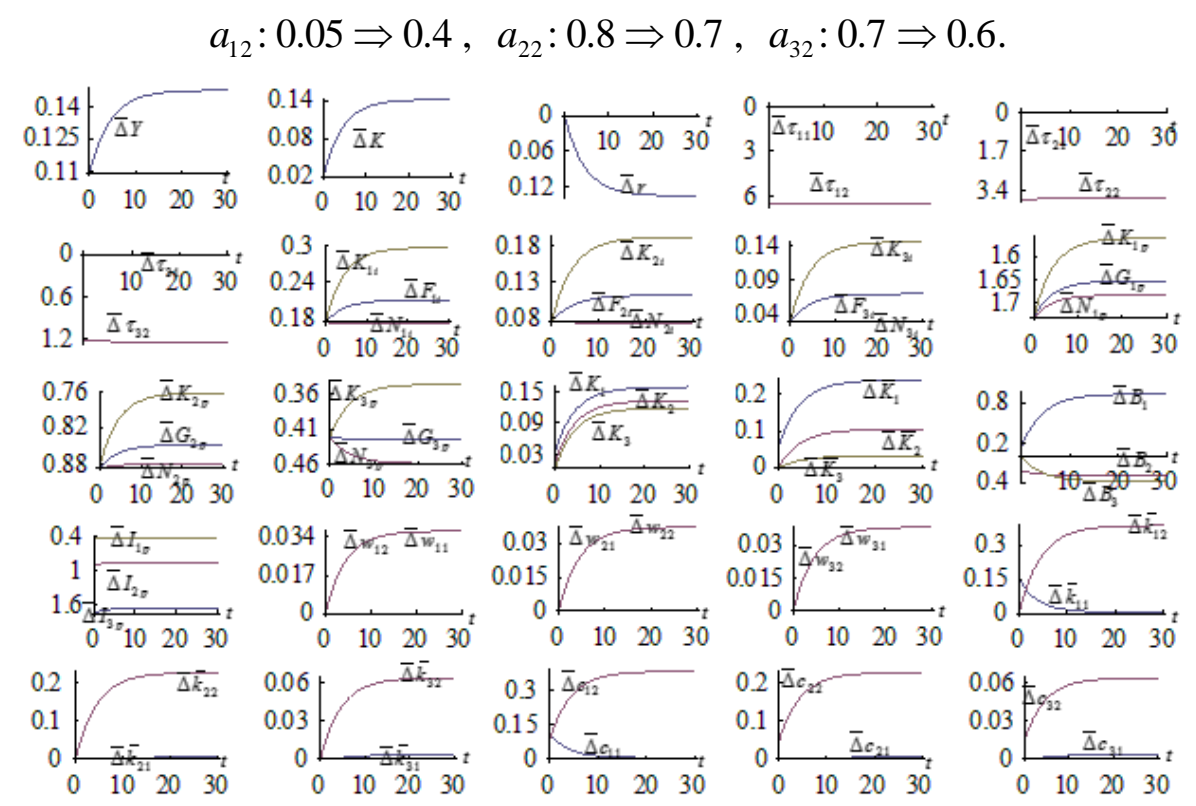

Figure 8. The Power Parameters in Group (j, 2)s' Taxation Equations are Reduced

Source: Author

The result is plotted in Figure 8. The change implies that group $(\mathrm{j}, 2) \mathrm{s}^{\prime}$ tax rates are less sensitive to changes in the disposable incomes. The global output and wealth are increased. The rate of interest falls. The tax rates on households $(j, 2) s$ are reduced. The public sectors shrink. The industrial sectors expand. The economies employ more capital stocks and have more wealth. Country 1's trade balance is improved, while the other two countries' trade balances are deteriorated. The wage rates are increased. The households on whom taxation has become lighter 
have more wealth and consume more. The other households' wealth and consumption levels are slightly changed.

\section{CONCLUDING REMARKS}

This paper built a multi-country growth model with nonlinear taxation and public goods. The dynamic machines of global development are national wealth accumulation and free trade. Different from most of theoretical growth models in neoclassical economics which deals with two-country world and each economy has a homogeneous population, our model deals with any number of national economies and each economy has heterogeneous population. In our approach each national economy consists of one industrial sector and one public sector and has any number of types of people. Our model integrates economic mechanisms of some well-known economic theories in a comprehensive framework. Each national economy is described according to Walrasian general economic theory. Capital accumulation follows the Solow model. Modelling public goods with nonlinear taxation is based on the literature of progressive taxation and economic growth. The trade pattern is modelled within the Oniki-Uzawa global growth model with two countries. We model household behavior on the basis of Zhang's concept of disposable income and utility function. The J-country global economic dynamics are described by $\mathrm{J}$ nonlinear differential equations. We simulated the model to show transitory processes and longterm equilibrium. We carried out comparative dynamic analysis in some parameters. It should be noted that as our model is built on the basis of some well-known economic theories and each of these theories has been developed with very complicated structures, we can generalize and extend our model according to the literature.

\section{Appendix: Proving the Lemma}

We now identify the differential equations and provide the procedure in the Lemma. From (3) and (13), we obtain

$z_{j} \equiv \frac{r+\delta_{k j}}{w_{j}}=\frac{\tilde{\alpha}_{j m} N_{j m}}{K_{j m}}, j=i, e$,

where $\tilde{\alpha}_{j m} \equiv \alpha_{j m} / \beta_{j m}$. From (A1), (2) and (3), we have

$$
r+\delta_{k j}=\alpha_{j i} A_{j i}\left(\frac{z_{j}}{\tilde{\alpha}_{j i}}\right)^{\beta_{j i}}, w_{j}=\frac{r+\delta_{k j}}{z_{j}} .
$$

From (A2) we also have

$$
z_{j}=\tilde{\alpha}_{j i}\left(\frac{r+\delta_{k j}}{\alpha_{j i} A_{j i}}\right)^{1 / \beta_{j i}}, w_{j q}=h_{j q} w_{j}
$$

Insert $w_{j} N_{j p}=\beta_{j p} I_{j p}$ in (11)

$$
N_{j p}=\beta_{j p} \sum_{q=1}^{Q_{j}}\left(\frac{r \bar{k}_{j q}}{w_{j}}+h_{j q}\right) \tau_{j q} N_{j q} .
$$

From (A1) and (14)-(16) we have 
$\sum_{j=1}^{J} \sum_{q=1}^{Q_{j}} \bar{k}_{j q} N_{j q}=\alpha+\sum_{j=1}^{J} \frac{\alpha_{j} N_{j p}}{z_{j}}$

where

$$
\alpha=\sum_{j=1}^{J} \frac{\tilde{\alpha}_{j i} N_{j}}{z_{j}}, \alpha_{j} \equiv \tilde{\alpha}_{j p}-\tilde{\alpha}_{j i}
$$

Insert (A4) in (A5)

$\sum_{j=1}^{J} \sum_{q=1}^{Q_{j}} \bar{k}_{j q} N_{j q}=\alpha+\sum_{j=1}^{J} \sum_{q=1}^{Q_{j}}\left(\bar{n}_{j q} \bar{k}_{j q}+n_{j q}\right) \tau_{j q}$

where

$$
\bar{n}_{j q} \equiv \frac{\alpha_{j} \beta_{j p} r N_{j q}}{w_{j} z_{j}}, n_{j q} \equiv \frac{\alpha_{j} \beta_{j p} h_{j q} N_{j q}}{z_{j}}
$$

We rewrite (A6) as

$$
\begin{aligned}
& \bar{k}_{11} N_{11}+\tilde{\alpha}-\left(\bar{n}_{11} \bar{k}_{11}+n_{11}\right) \tau_{11}=0, \\
& \text { where } \tilde{\alpha}=-\alpha+\sum_{q=2}^{Q_{1}} \bar{k}_{1 q} N_{1 q}+\sum_{j=2}^{J} \sum_{q=}^{Q_{j}} \bar{k}_{j q} N_{j q}-\sum_{q=2}^{Q_{1}}\left(\bar{n}_{1 q} \bar{k}_{1 q}+n_{1 q}\right) \tau_{1 q}-\sum_{j=2}^{J} \sum_{q=2}^{Q_{j}}\left(\bar{n}_{j q} \bar{k}_{j q}+n_{j q}\right) \tau_{j q} .
\end{aligned}
$$

We specify

$$
\tau_{11}=b_{11}+\tilde{b}_{11} w_{11}+\tilde{b}_{11} r \bar{k}_{11} .
$$

Insert (A8) in (A7)

$\bar{k}_{11}^{2}+m_{1} \bar{k}_{11}+m_{2}=0$,

where

Solve (A9)

$$
m_{1} \equiv \frac{n_{11} \tilde{b}_{11} r-N_{11}+\bar{n}_{11} \hat{b}_{11}}{\bar{n}_{11} \tilde{b}_{11} r}, m_{2} \equiv \frac{n_{11} \hat{b}_{11}-\tilde{\alpha}}{\bar{n}_{11} \tilde{b}_{11} r}, \hat{b}_{11} \equiv b_{11}+\tilde{b}_{11} w_{11}
$$

$$
\bar{k}_{11}=\varphi\left(z_{1},\left\{\bar{k}_{j q}\right\}\right) \equiv \frac{-m_{1} \pm \sqrt{m_{1}^{2}-4 m_{2}}}{2} .
$$


In our simulation the following solution of (A10) has a meaningful solution

$$
\bar{k}_{11}=\frac{-m_{1}+\sqrt{m_{1}^{2}-4 m_{2}}}{2} \text {. }
$$

We describe a computational procedure now show The following procedure shows how to express the variables as functions $z_{1}$ and $\left\{\bar{k}_{j q}\right\}$ as follows: $r$ and $w_{j}$ with (A2) $\rightarrow w_{j q}$ and $z_{j}$ from (A3) $\rightarrow \bar{k}_{1}$ by (A10) $\rightarrow y_{0 j q}$ by (4) $\rightarrow \tau_{j q}$ by (5) $\rightarrow y_{j q}$ by (6) $\rightarrow \hat{y}_{j q}$ by (6) $\rightarrow c_{j q}$ and $s_{j q}$ by (9) $\rightarrow I_{j q}$ by (11) $\rightarrow G_{j}$ by (12) $\rightarrow N_{j p}$ by (A4) $\rightarrow N_{j i}$ by (15) $\rightarrow K_{j m}$ by (A1) $\rightarrow$ $\rightarrow F_{j i}$ by (2) $\rightarrow K_{j}$ by (14) $\rightarrow K_{j}$ by (14) $\rightarrow \bar{K}_{j}$ by (15) $\rightarrow B_{j}$ by (21). From this procedure, and (13)-(15), we have

$\dot{\bar{k}}_{11}=\Omega_{0}\left(z_{1},\left\{\bar{k}_{j q}\right\}\right) \equiv s_{11}-\bar{k}_{11}$,

$\dot{\bar{k}}_{j q}=\Omega_{j q}\left(z_{1},\left\{\bar{k}_{j q}\right\}\right) \equiv s_{j q}-\bar{k}_{j q},(j, q) \neq(1,1)$.

Take derivatives of (A10) in $t$

$\dot{\bar{k}}_{11}=\frac{\partial \varphi}{\partial z_{1}} \dot{z}_{1}+\sum_{(j, q) \neq(1,1)} \frac{\partial \varphi}{\partial \bar{k}_{j q}} \dot{\bar{k}}_{j q}$.

Insert (A12) in (A13)

$\dot{\bar{k}}_{11}=\frac{\partial \varphi}{\partial z_{1}} \dot{z}_{1}+\sum_{(j, q) \neq(1,1)} \Omega_{j q} \frac{\partial \varphi}{\partial \bar{k}_{j q}}$.

Equal the right-hand sides of (A14) and (A11)

$\dot{z}_{1}=\Omega_{11}\left(z_{1},\left\{\bar{k}_{j q}\right\}\right) \equiv\left(\Omega_{0}-\sum_{(j, q) \neq(1,1)} \Omega_{j q} \frac{\partial \varphi}{\partial \bar{k}_{j q}}\right)\left(\frac{\partial \varphi}{\partial z_{1}}\right)^{-1}$.

In summary, we confirmed the Lemma.

\section{REFERENCES}

Abel, A., Bernanke, B.S., \& Croushore, D. (2007). Macroeconomics. New Jersey: Prentice Hall. Acemoglu, D. (2002). Technical change, inequality and labor market, Journal of Economic Literature, 15, 7-72

Agénor, P.-R. (2011). Schooling and Public Capital in a Model of Endogenous Growth. Economica, 78, 108-132

Aghion, P., Howitt, P., \& Violante, G.L. (2002). General purpose technology and wage inequality, Journal of Economic Growth, 7, 315-45

Atkeson, A., \& Kehoe, P. (2000). Paths of development for early- and late- boomers in a dynamic Heckscher-Ohlin model,' Research Staff Report 256, Federal Reserve Bank of Mineapolis

Azariadis, C. (1993). Intertemporal Macroeconomics. Oxford: Blackwell

Baier, S.L., \& Glomm, G. (2001). Long-run Growth and Welfare Effects of Public Policies with Distortionary Taxation. Journal of Economic Dynamics and Control, 25, 2007-42 
Barro, R.J. (1990). Government Spending in a Simple Model of Endogenous Growth. Journal of Political Economy, 98, S103-25

Barro, R.J., \& Sala-i-Martin, X. (1995). Economic Growth. New York: McGraw-Hill, Inc.

Baxter, M. (1992). Fiscal policy, specialization, and trade in the two-sector model: return of Ricardo? Journal of Political Economy, 100, 713-44

Bos, J.W.B., Economidou, C., Koetter, M., \& Kolari. J.W. (2010). Do all countries grow alike? Journal of Development Economics, 91, 113-27

Brecher, R.A., Chen, Z.Q., \& Choudhri, E.U. (2002). Absolute and comparative advantage, reconsidered: the pattern of international trade with optimal saving, Review of International Economics, 10, 645-56

Burmeister, E., \& Dobell, A.R. (1970). Mathematical Theories of Economic Growth. London: Collier Macmillan Publishers

Cameron, G., Proudman, J., \& Redding, S. (2005). Technology and convergence, R\&D, trade and productivity growth, European Economic Review, 49, 775-807

Caselli, F., Esquivel, G., \& Lefort, F. (1996). Reopening the convergence debate: a new look at cross-country growth empirics, Journal of Economic Growth, 1, 363-89

Cazzavillan, G. (1996). Public Spending, Endogenous Growth, and Endogenous fluctuations. Journal of Economic Theory 71, 394-415

Chen, B. L. (2006). Public Capital, Endogenous Growth, and Endogenous Fluctuations. Journal of Macroeconomics 28, 768-74

Chen, S.H., \& Guo, J. T. (2013). Progressive Taxation and Macroeconomic (In) Stability with Productive Government Spending. Journal of Economic Dynamics and Control 37, 951-63

Chen, S.H., \& Guo, J.T. (2014). Progressive Taxation and Macroeconomic (In) stability with Utility-Generating Government Spending. Journal of Macroeconomics, 42, 174-83

Chen, S.H., \& Ravallion, M. (1997). What can new survey data tell us about recent changes in distribution and poverty? The World Bank Economic Review, 11, 357-82

Chen, Z. (1992). Long-run equilibria in a dynamic Heckscher-Ohlin model, Canadian Journal of Economics, 23, 923-43

Eaton, J. (1987). A dynamic specific-factors model of international trade, Review of Economic Studies, 54, 325-38

Fernández, E., Novales, A., \& Ruiz, J. (2004). Indeterminacy under Non-separability of Public Consumption and Leisure in the Utility Function. Economic Modelling, 21, 409-28

Findlay, R. (1984). Growth and development in trade models, in Jones, R.W. and Kenen, R.B. (Eds.): Handbook of International Economics, North-Holland, Amsterdam

Frenkel, J.A., \& Razin, A. (1987). Fiscal Policy and the World Economy, MIT Press, MA, Cambridge

Galor, O., \& Zeira, J. (1993). Income distribution and macroeconomics, Review of Economic Studies, 60, 35-52

Glomm, G., \& Ravikumar, B. (1997). Productive Government Expenditures and Long-run Growth. Journal of Economic Dynamics and Control, 21, 183-204

Greiner, A. (2007). An Endogenous Growth Model with Public Capital and Sustainable Government Debt. Japanese Economic Review, 58, 345-61

Grier, K., \& Grier, R. (2007). Only income diverges: a neoclassical anomaly, Journal of Development Economics, 84, 25-45

Guo, J.-T., \& Harrison, S.G. (2008). Useful Government Spending and Macroeconomic (In)Stability Under Balanced-Budget Rules. Journal of Public Economic Theory, 10, 383-97

Hall, R.E., \& Jones, C.I. (1999). Why do some countries produce so much more output per worker than others? Quarterly Journal of Economics, 114, 83-116 
Hu, Y., Ohdoi, R., \& Shimomura, K. (2008). Indeterminacy in a Two-Sector Endogenous Growth Model with Productive Government Spending. Journal of Macroeconomics, 30, 1104-1123

Ikeda, S., \& Ono, Y. (1992). Macroeconomic dynamics in a multi-country economy - a dynamic optimization approach, International Economic Review, 33, 629-44

Jones, L., \& Manuelli, R.E. (1997). The Sources of Growth. Journal of Economic Dynamics and Control, 21, 75-114

Miles, D., \& Scott, A. (2005). Macroeconomics - Understanding the Wealth of Nations. Chichester: John Wiley \& Sons, Ltd.

Nishimura, K., \& Shimomura, K. (2002). Trade and indeterminacy in a dynamic general equilibrium model, Journal of Economic Theory, 105, 244-60

Oniki, H., \& Uzawa, H. (1965). Patterns of trade and investment in a dynamic model of international trade, Review of Economic Studies, 32, 15-38

Palivos, T., Yip, C.Y., \& Zhang, J. (2003). Transitional Dynamics and Indeterminacy of Equilibria in an Endogenous Growth Model with a Public Input. Review of Development Economics, 7, 86-98

Pasinetti, L.L. (1974). Growth and Income Distribution - Essays in Economic Theory, Cambridge University Press, Cambridge

Pritchett, L. (1997). Divergence: big time, Journal of Economic Perspectives, 11, 3-18

Raurich, X. (2003). Government Spending, Local Indeterminacy and Tax Structure. Economica, $70,639-53$

Samuelson, P.A. and Modigliani, F. (1966). The Pasinetti paradox in neo-classical and more general models, The Review of Economic Studies, 33, 269-301

Sorger, G. (2002). On the multi-country version of the Solow-Swan model, The Japanese Economic Review, 54, 146-64

Stiglitz, J.E. (1970). Factor price equalization in a dynamic economy, Journal of Political Economy, 78, 456-88

Tachibanaki, T. (2006). Inequality and poverty in Japan, Japanese Economic Review, 57, $1-27$

Turnovsky, S.J. (2000). Fiscal Policy, Elastic Labor Supply, and Endogenous Growth. Journal of Monetary Economics, 45, 185-210

Turnovsky, S.J. (2004). The Transitional Dynamics of Fiscal Policy: Long-Run Capital Accumulation and Growth. Journal of Money, Credit, and Banking, 36, 883-910

Zhang, J. (2000). Public Services, Increasing Returns, and Equilibrium Dynamics. Journal of Economic Dynamics and Control, 24, 227-46

Zhang, W.B. (1993). Woman's Labor Participation and Economic Growth - Creativity, Knowledge Utilization and Family Preference. Economics Letters, 42, 105-10

Zhang, W.B. (2005). Economic Growth Theory, Ashgate, London

Zhang, W.B. (2008). International Trade Theory: Capital, Knowledge, Economic Structure, Money and Prices over Time and Space, Springer, Berlin

Zhang, W.B. (2015). Progressive Income Taxation and Economic Growth with Endogenous Labor Supply and Public Good. European Journal of Business and Economic Studies $3(1), 230-47$

Zhang, W.B. (2016). Income and Wealth Inequality with Progressive Income Taxation in an Integrated Walrasian-General Equilibrium and Neoclassical-Growth Theory. International Journal of Green Economics, 10(1), 15-31 